\title{
Risk Assessment and Protective Effect of Respirators on Airborne Paraquat Exposure during Simulated Spraying Operations
}

\author{
Sunisa Chaiklieng ${ }^{1, *}$, Chuthamas Chagkornburee ${ }^{2}$, \\ Piyada Songsermsakul ${ }^{3}$ and Vichai Pruktharathikul ${ }^{1}$
}

${ }^{I}$ Department of Environmental Health, Occupational Health and Safety, Faculty of Public Health, Khon Kaen University, Khon Kaen 40002, Thailand

${ }^{2}$ Master of Science Program in Occupational Health and Safety, Khon Kaen University, Khon Kaen 40002, Thailand

${ }^{3}$ Division of Pharmacology and Toxicology, Faculty of Pharmaceutical Sciences, Khon Kaen University, Khon Kaen 40002, Thailand

('Corresponding author's e-mail: csunis@kku.ac.th)

Received: 18 July 2020, Revised: 27 April 2021, Accepted: 30 April 2021

\begin{abstract}
Paraquat (PQ) is widely used as a herbicide in Thailand. The aim of this study was to evaluate the health risk and protective effect of respirators during simulated PQ spraying operations in an experimental chamber. Additional data were collected from the interviews of PQ sprayers. Airborne PQ concentrations were collected from an experimental spray chamber employing controlled-rate sprayers of solutions (paraquat dichloride in water) and were lower than $50 \mu \mathrm{g} / \mathrm{m}^{3}$ (the standard regulation). Air sampling through a polytetrafluoroethylene filter membrane was performed under the conditional settings of inside and outside respirators, and analysed by using a HPLC-UV detector following NIOSH method 5003. The average PQ concentrations inside the certified respirators (cartridge, cup-shaped mask, surgical mask) were significantly lower than those outside of the respirators $\left(4.30 \pm 2.63 \mu \mathrm{g} / \mathrm{m}^{3} \mathrm{vs} .19 .12 \pm 16.65\right.$ $\mu \mathrm{g} / \mathrm{m}^{3}$ ), which was not found with convenient sponge masks. Human health risk assessment on short-term and long-term exposure following US.EPA guide estimation showed that cartridge respirators and cupshaped masks significantly decreased the risk (hazard quotient) of adverse health effects ( $p$-value $<0.05$ ) among the PQ sprayers. As a result, the PQ sprayers should be aware of preventive action and use a qualified mask/respirator to protect against exposure to airborne PQ and chronic health effects.
\end{abstract}

Keywords: Risk assessment, Airborne paraquat, Cartridge respirator, Testing chamber

\section{Introduction}

Paraquat (PQ), a hazardous chemical, is classified as a non-selective contact herbicide. It is widely used in broad spectrum weed control. A previous study in Malaysia [1] found that the airborne PQ concentration during spraying was slightly higher than the Threshold Limit Value (TLV-TWA; 100 $\mu \mathrm{g} / \mathrm{m}^{3}$ ) recommended by the National Institute of Occupational Safety and Health [2]. Other studies have shown upper airway irritation as an adverse respiratory symptom from PQ exposure [3-5]. In Thailand, 50 percent of farmers who had used PQ complained of upper airway irritation and of those, more than 7 percent reported breathing difficulty [6,7].

A total of $9,943,933 \mathrm{~kg}$ of PQ, valued at 794,856,811 baht $(24,775,787 \mathrm{USD})$, was imported into Thailand in 2019 [8]. On May 17, 2020, a report from the Thai Ministry of Public Health (Health Data Center: HDC) [9] showed that 2,176 patients had been treated due to toxic pesticide exposure, with all careers in Thailand considered, while the morbidity rate of all pesticide poisoning was 4.76 per 100,000 target population, and the morbidity rate of specific herbicides was 0.85 per 100,000 target population. Moreover, the morbidity rate related to respiratory disease in the working age group of 15 - 59 years old was 5,797.76 per 100,000 population.

Since there had been few studies of health risk assessment on PQ exposure and protective actions of knapsack sprayers, this study was designed to quantify the health risk of exposure to airborne PQ and the 
effectiveness of protection by the respirator use of PQ sprayers during simulated spray operations, in the experiment.

\section{Materials and methods}

This study was designed to study knapsack sprayers with and without respirator use. Data were collected both in the field, by interviewing the knapsack sprayers, and carrying out an experiment by simulating conditions of PQ spray operation in the chemical spray testing chamber. Air samples were collected from the experimental operation in the spray chamber under conditions before the laboratory analysis of PQ concentration. The simulation chamber was made of clear acrylic $\left(80 \times 90 \times 120 \mathrm{~cm}^{3}\right)$, and part of the rear wall contained a tiny supplementary exhaust fan (at an exceedingly low wind speed) to control air flow in the direction of the monitoring sampler during PQ spraying, as demonstrated in Figure 1.

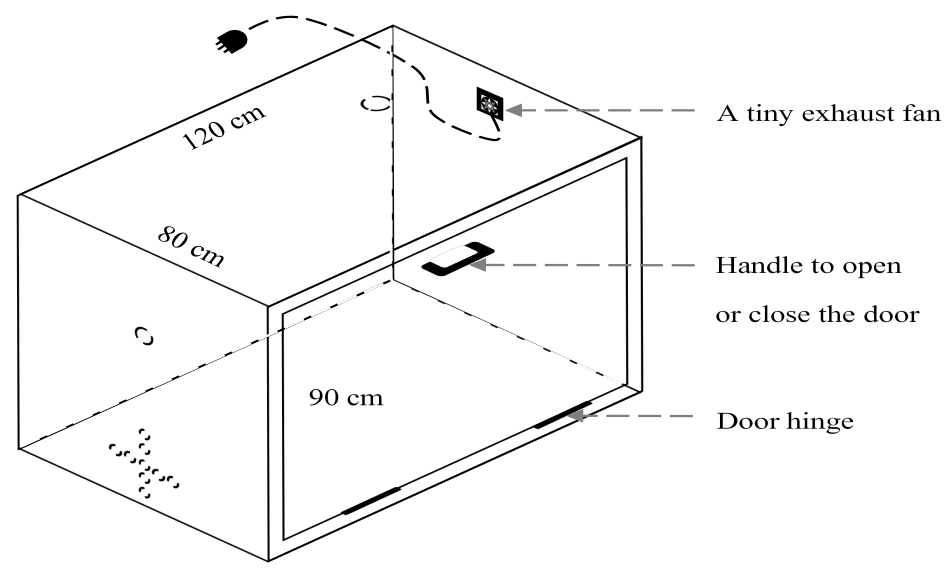

Figure 1 The simulation chamber was made of clear acrylic $\left(80 \times 90 \times 120 \mathrm{~cm}^{3}\right)$, and contained a tiny exhaust fan placed on the rear wall and a handle to open/ close the door on one of the side walls.

\section{Interview questionnaire}

An interview questionnaire was used to collect the personal and work characteristics of knapsack sprayers. Participants were chosen by using purposive sampling among pesticide sprayers in Nampong district of Khon Kaen province, in the north-east of Thailand. There were 29 knapsack sprayers who met the inclusion criteria of this study, which were as follows. Participants 1) were $\geq 18$ years old, 2) sprayed paraquat dichloride at least once a year, and 3) had volunteered to participate in the study. The adverse symptoms of the respiratory system related to PQ toxicity and other information included in the questionnaire were developed from previous studies [10,11] and approved by five experts (occupational health and safety officer, epidemiologist, medical doctor, toxicologist and pharmacologist) for content validity before collection of data. In that interview questionnaire, the sprayers were also asked about respiratory protection used in order to select a type for the experimental risk assessment on PQ exposure. This study was approved by the Human Research Ethics Committee, Khon Kaen University (HE 592418).

\section{Sampling method and analysis}

Paraquat dichloride, approximately $2.50 \mathrm{ml}$ in $500 \mathrm{ml}$ water $(\mathrm{v} / \mathrm{V})$, was mixed for solution preparation (the commonly recommended preparation for farmers' use). The solution was generated to be sprayed in the chamber manually, through the hole of the designed chamber, once every 5 min for $25 \mathrm{~min}$. From the simulated spraying, the concentrations of airborne PQ from the prepared solution (v/V: 2.5/500) were equivalent to a maximum of $46.08 \mu \mathrm{g} / \mathrm{m}^{3}$ in the experimental-setting chamber. That simulated spraying operation kept the PQ concentrations (outside respirators) within the safety standards of $8 \mathrm{~h}$ working (TLV-TWA, ACGIH) [12] and Thailand's labour regulations [13], which were lower than 50 $\mu \mathrm{g} / \mathrm{m}^{3}$.

Airborne paraquat concentration in the simulation chamber was collected through a polytetrafluoroethylene (PTFE) filter using a personal pump with a flow rate of 2 litres/min for 25 min to a total volume of 50 litres. The temperature during simulated spraying was $26.0 \pm 1.8{ }^{\circ} \mathrm{C}$. There was a 
model, which was a nose perforated via airhost with two pieces of cassette connected to the personal pump. The out-of-respirator condition of PQ concentration measurement was created by holding the monitoring sampler in a stand and clamp to represent no use of a respirator during spraying operations. On the other hand, the in-respirator condition of PQ concentration measurement was instead created inside the nose of a mannequin model behind a respirator at the same time, and it was the same height as the one shown in Figure 2 This air monitoring was performed as per the guidelines [14].

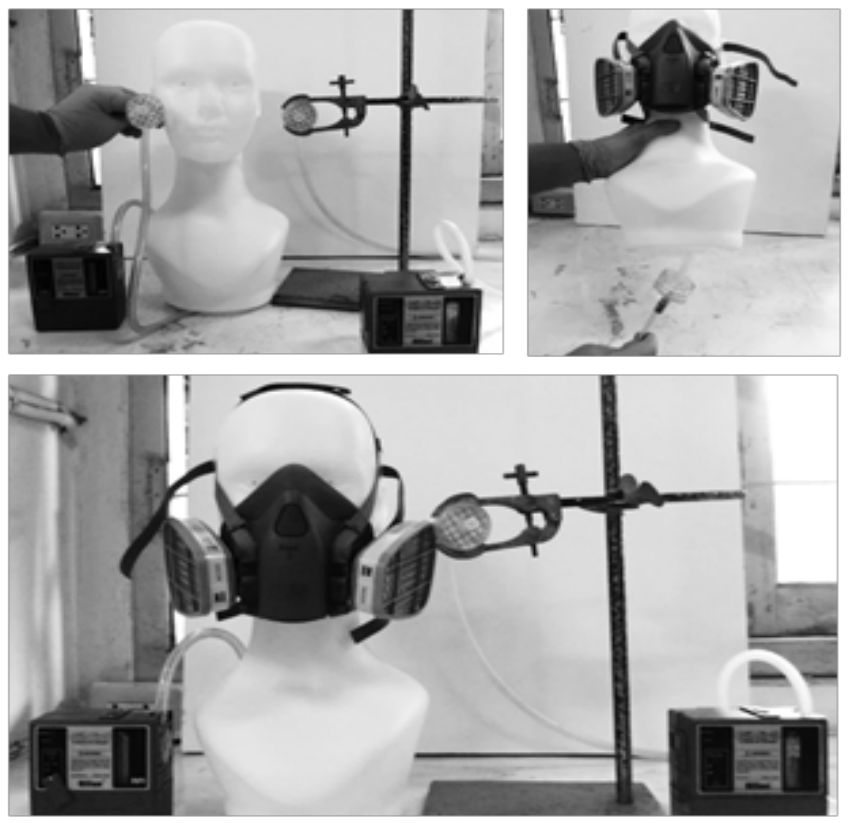

Figure 2 In-respirator and out-of-respirator PQ monitoring.

\section{Paraquat analysis}

Method 5003 [14] with some modification was employed for both sample preparation and paraquat analysis. Samples obtained through PTFE were transferred to plastic test tubes and $10 \mathrm{ml}$ of 0.01 normality $(\mathrm{N}) \mathrm{HCl}$ [1] was added to each and left for overnight equilibration. The samples were later centrifuged at $200 \mathrm{rpm}$ for $60 \mathrm{~min}$. The method showed good levels of recovery $(92.5-108.9 \%)$. Samples of $10 \mu \mathrm{l}$ were injected into the High Performance Liquid Chromatography (HPLC) with a UV detector at $\lambda 254 \mathrm{~nm}$. The column used was a $\mu$ Bondapak C18 column, $125 \AA, 10 \mu \mathrm{m}, 3.9 \mathrm{~mm} \times 300 \mathrm{~mm}$, Water, USA. The mobile phase consisted of $40 \%$ acetonitrile and $60 \% 0.01 \mathrm{M} \mathrm{NaCl}(\mathrm{pH} 3.2)$. All solvents were filtered and degassed before usage. An isocratic flow rate at $1 \mathrm{ml} / \mathrm{min}$ was run and the retention time was $2.18-2.28 \mathrm{~min}$. The six standard solutions of $0.05,0.1,0.5,1,5$, and $10 \mu \mathrm{g} / \mathrm{ml}$ were used to prepare a standard curve, and 1 and $10 \mu \mathrm{g} / \mathrm{ml}$ solution were used for precision study. Both repeatability and inter-day precision showed less than $5 \%$ of the relative standard deviation (RSD). The $\mathrm{R}$-squared $\left(\mathrm{R}^{2}\right)$ value for the standard curve was 0.998 , which means the regression line fit the data well. The limit of detection (LOD) was $0.035 \mu \mathrm{g} / \mathrm{ml}$ and the limit of quantification (LOQ) was $0.095 \mu \mathrm{g} / \mathrm{ml}$. The laboratory met the requirements of Enhancement of Safety Practice of Research Laboratory in Thailand (ESPReL).

Inhalation intake and health risk assessment on PQ exposure

The inhalation intake was estimated by following US.EPA (1991) [15].

Intake $=(\mathrm{C} \times \mathrm{IR} \times \mathrm{EF} \times \mathrm{ED}) /(\mathrm{BW} \times \mathrm{AT})$

$\mathrm{C}=$ Average airborne $\mathrm{PQ}$ concentration from the experiment during spraying operations in the chamber

IR = Inhalation or contact rate $=20 \mathrm{~m}^{3} /$ day

$\mathrm{EF}=$ Exposure frequency from interview (days/year)

$\mathrm{ED}=$ Exposure duration $=30$ years

$\mathrm{BW}=$ Body weight from interview $(\mathrm{kg})$

$\mathrm{AT}=$ Average time $=30$ years 


\section{Hazard Quotient (HQ)}

The non-specific organ HQ was calculated by comparing the intake to the reference of acceptable exposure level, or the long-term AOEL $(0.4 \mu \mathrm{g} / \mathrm{kg} / \mathrm{day})$ and short-time AOEL $(0.5 \mu \mathrm{g} / \mathrm{kg} / \mathrm{day})$ recommended by the European Commission; EU [16], and the specific organ HQ was calculated by using the reference dose (RfD) of chronic pneumonitis $(4.5 \mu \mathrm{g} / \mathrm{kg} / \mathrm{day})$ set by the Integrated Risk Information System; IRIS [17]. An unacceptable risk was indicated when the estimated HQ of daily intake was higher than $1(\mathrm{HQ}>1)$.

\section{Results and discussion}

Personal characteristics and adverse symptoms of sprayers

The 29 volunteer PQ knapsack sprayers were both male $(86.21 \% ; n=25)$ and female $(13.79 \% ; n=$ 4). The age range was $25-79$ years $(53.86 \pm 11.20)$. Body weight ranged from $43-75 \mathrm{~kg}(56.69 \pm 7.83)$. The plantations of sprayers were rice $(82.76 \% ; \mathrm{n}=24)$, sugar cane $(65.52 \% ; \mathrm{n}=19)$, cassava $(27.59 \%$; $\mathrm{n}=8)$, cucumber $(24.14 \% ; \mathrm{n}=7)$, guava $(20.69 \% ; \mathrm{n}=6)$, long bean $(17.24 \% ; \mathrm{n}=5)$, and corn field $(3.45 \% ; \mathrm{n}=1)$. PQ dichloride was used at $0.1-2,400$ litres/year (maximum $=2,400$ litres, average $=$ $148.18 \pm 477.85$ ). Spraying experience ranged from $1-46$ years (average $=18.14 \pm 12.05$ ). Experience of adverse symptoms related to the respiratory system is presented in Table 1.

Table 1 Adverse symptoms related to paraquat toxicity experienced by the sprayers $(n=29)$.

\begin{tabular}{lrl}
\hline Adverse symptoms & n & $(\mathbf{\%})$ \\
\hline Throat irritation & 15 & $(51.72 \%)$ \\
Nose irritation & 6 & $(20.69 \%)$ \\
Runny nose (not from flu) & 4 & $(13.79 \%)$ \\
Wheezing and difficulty breathing & 4 & $(13.79 \%)$ \\
Chest pain & 2 & $(6.90 \%)$ \\
\hline
\end{tabular}

The respiratory protective equipment (respirator/mask) used by PQ sprayers

The PQ knapsack sprayers who were farmers of sugar cane, cassava, rice, and corn normally had respiratory protection $(96.55 \%)$. The most reported type of respirator used was surgical mask $(41.38 \%)$, followed by cloth mask (37.93 \%), and sponge mask (24.14\%), respectively. Other types of respiratory protection used during spraying are presented in Table 2.

Table 2 Different types of respiratory protective equipment used by PQ sprayers $(n=29)$.

\begin{tabular}{cccccc}
\hline \multicolumn{5}{c}{ Respiratory protective equipment; number (\%) } \\
\hline $\begin{array}{c}\text { Balaclava } \\
\text { face mask }\end{array}$ & Surgical mask & Cloth mask & Sponge mask & T-shirt & Loincloth \\
\hline & & & & & \\
& & & & & \\
22 & 12 & 11 & 7 & 3 & 2 \\
$(75.86 \%)$ & $(41.38 \%)$ & $(37.93 \%)$ & $(24.14 \%)$ & $(10.34 \%)$ & $(6.90 \%)$ \\
\hline
\end{tabular}

Airborne PQ concentrations in the simulated spraying operation chamber

In an experimental spraying simulation, the PQ concentration outside the respiratory protective equipment condition was controlled by adjusting the rate of spray so it remained lower than the safety standard of $8 \mathrm{~h}$. working (TLV-TWA, ACGIH) [12] and Thailand's labour standard $\left(50 \mu \mathrm{g} / \mathrm{m}^{3}\right)$ [13]. Since the respirators which were mostly used among sprayers in the field were surgical mask, cloth mask 
or convenient sponge mask, the experiment was designed to test two of those types (the certified surgical mask and sponge mask). Regarding the convenient mask (sponge mask), it can be easily found in the market as a fashion mask in Thailand. The certified standard cup-shaped mask and the cartridge respirator were added to test their protective effect against airborne PQ concentrations in the simulated spraying chambers.

From the experiments on certified respirators/masks, it was found that the average concentration outside the respirators was $19.12 \pm 16.65 \mu \mathrm{g} / \mathrm{m}^{3}$ (range $=2.15-46.08 \mu \mathrm{g} / \mathrm{m}^{3}, 95^{\text {th }}$ percentile $=38.31$ $\mu \mathrm{g} / \mathrm{m}^{3}, \mathrm{IQR}=21.15 \mu \mathrm{g} / \mathrm{m}^{3}$ ). The concentrations ranged from $10.52 \%$ to $92.16 \%$ of the standard recommended by ACGIH [12] and $1.05 \%$ to $9.22 \%$ of the Thailand standard recommended by the Department of Labour Protection and Welfare [13]. The mean concentration inside certified respirators (cartridge, cup-shaped mask, and surgical mask) was $4.30 \pm 2.63 \mu \mathrm{g} / \mathrm{m}^{3}$ (range $=1.17-7.42 \mu \mathrm{g} / \mathrm{m}^{3}, 95^{\text {th }}$ percentile $=7.36 \mu \mathrm{g} / \mathrm{m}^{3}, \mathrm{IQR}=4.26 \mu \mathrm{g} / \mathrm{m}^{3}$ ). This inside concentration was much lower than that outside the respirators and the standard recommendation [12,13]. The concentrations ranged from $2.34 \%$ to 14.85 $\%$ of the standard recommended by ACGIH [12] and $0.23 \%$ to $1.48 \%$ of the Thailand standard [13]. Overall concentrations were lower than all standards recommended by USA NIOSH [2], ACGIH [12], OSHA [18], and the Thailand labour regulations [13].

Table 3 Concentration of airborne PQ inside and outside respirators during PQ spraying operations in the simulation chambers.

\begin{tabular}{cccccc}
\hline \multirow{2}{*}{ Condition } & \multicolumn{2}{c}{$\begin{array}{c}\text { Certified respirator/mask } \\
\text { (cartridge, cup-shaped, surgical); }(\mathbf{n}=\mathbf{6})\end{array}$} & \multicolumn{2}{c}{ The convenient sponge mask } \\
$(\mathbf{n}=\mathbf{6})$
\end{tabular}

*The concentration decrease from out-of-respirator conditions to in-respirator conditions for each of the certified respirators was $89.95 \%, 72.63 \%$, and $38.32 \%$ for cartridge, cup-shaped mask, and surgical mask, respectively.

**A significantly lower concentration, at a $p$-value $<0.05$, was observed according to the WilcoxonMann-Whitney test.

\section{Protection against airborne $P Q$ concentrations by certified respirator use}

The most effective of the protective respirators was the cartridge respirator, which was indicated by the lower concentrations of PQ inside the respirators when compared to outside the respirators. The PQ concentration inside the cartridge (average $=3.97 \pm 1.45, \mathrm{IQR}=1.02 \mu \mathrm{g} / \mathrm{m}^{3}$ ) was about 90 percent lower than the PQ concentration outside the cartridge (average $=39.50 \pm 9.31, \mathrm{IQR}=6.58 \mu \mathrm{g} / \mathrm{m}^{3}$ ). It was shown that use of the cup-shaped mask (average $=1.66 \pm 0.69, \mathrm{IQR}=0.49 \mu \mathrm{g} / \mathrm{m}^{3}$ ), resulted in a 72.63 percent decrease from the concentration outside the respirator (average $=6.06 \pm 1.13 \mu \mathrm{g} / \mathrm{m}^{3}, \mathrm{IQR}=0.80$ ) and use of the surgical mask (average $=7.29 \pm 0.19, \mathrm{IQR}=0.14 \mu \mathrm{g} / \mathrm{m}^{3}$ ) resulted in a 38.32 percent decrease from the concentration outside the respirator (average $=11.81 \pm 4.52, \mathrm{IQR}=3.20 \mu \mathrm{g} / \mathrm{m}^{3}$ ). On the other hand, use of the convenient sponge mask resulted in no significant difference between concentrations inside and outside the mask; the PQ concentration inside the mask (average $=6.49 \pm 0.62, \mathrm{IQR}=0.44 \mu \mathrm{g} / \mathrm{m}^{3}$ ) was slightly higher than that outside the respirator (average $=5.38 \pm 0.09, \mathrm{IQR}=0.07 \mu \mathrm{g} / \mathrm{m}^{3}$ ), or $120.56 \%$ of the outside concentration.

Inhalation risk assessment

Exposure to airborne paraquat concentrations was estimated while spraying into the simulation chamber. All input values in the intake equation follow the US.EPA [14] in collaboration with BW-Body weight and EF-Exposure frequency (days/year) from the interviews. 


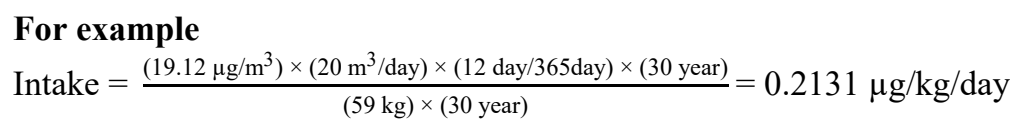

Risk was indicated by the hazard quotient, which was calculated by comparing the intake to the reference dose of exposure for long-term, short-term, and chronic pneumonitis effects. A hazard quotient value of more than 1 represented a significant risk of health effects (HQ $>1)$.

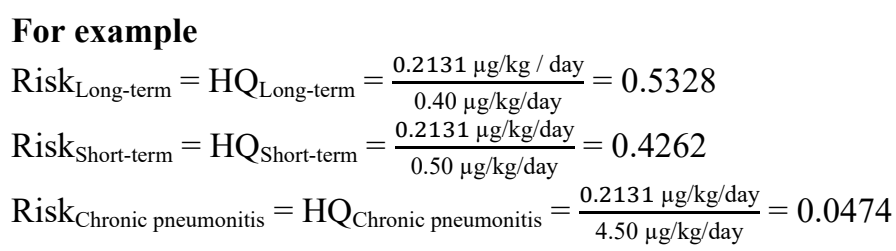

Analysis of concentrations outside respiratory protective equipment under all conditions revealed that the intake estimations of sprayers were between $0.016-7.053 \mu \mathrm{g} / \mathrm{kg} / \mathrm{day}$, while concentrations inside respiratory protective equipment showed that the intakes were between $0.004-1.588 \mu \mathrm{g} / \mathrm{kg} / \mathrm{day}$. Among the 29 sprayers, the risk estimations in cases without respirators indicated a potential health risk $(\mathrm{HQ}>1)$ in some sprayers. There were $20.69 \%$ of workers with higher than acceptable risk of exposure when comparing to the recommended $\mathrm{AOEL}_{\text {long-term }}(0.40 \mu \mathrm{g} / \mathrm{kg} /$ day $)$ [16] and $17.24 \%$ of workers when comparing to the recommended $\mathrm{AOEL}_{\text {short-term }}(0.50 \mu \mathrm{g} / \mathrm{kg} / \mathrm{day})$ [16]. Chronic pneumonitis was indicated in $3.45 \%$ of sprayers when comparing to the reference dose $(4.50 \mu \mathrm{g} / \mathrm{kg} / \mathrm{day})$ [17].

Regarding respirator use, HQ values decreased differently according to use of different respirators. Effective protection against PQ inhalation risk (HQ $>1$ ) among sprayers is presented in Table 4. The convenient sponge mask and surgical mask, 2 types in general use among sprayers, did not significantly decrease the HQ of short-term and long-term exposure. The qualified standard cup-shaped mask and cartridge respirator could significantly decrease the health risk of sprayers, in both short-term and longterm exposure.

Table 4 Risk (HQ) of exposure to paraquat among sprayers with the use of cup-shaped mask, sponge mask, surgical mask and cartridge $(n=29)$.

\begin{tabular}{llccc}
\hline \multirow{2}{*}{ Respirator/mask } & \multirow{2}{*}{ Exposure } & \multicolumn{2}{c}{ Risk condition (HQ) } & \multirow{2}{*}{ p-value } \\
\cline { 2 - 4 } Cartridge & Long - term & $0.083-36.417$ & $0.008-3.660$ & $<0.001^{*}$ \\
\cline { 2 - 4 } & Short - term & $0.067-29.134$ & $0.007-2.928$ & $<0.001^{*}$ \\
\hline \multirow{2}{*}{ Cup-shaped } & Long - term & $0.013-5.583$ & $0.004-1.528$ & $0.004^{*}$ \\
\cline { 2 - 4 } & Short - term & $0.010-4.467$ & $0.003-1.223$ & $0.004^{*}$ \\
\hline \multirow{2}{*}{ Surgical mask } & Long - term & $0.025-10.893$ & $0.015-6.719$ & 0.240 \\
\cline { 2 - 4 } Sponge mask & Short - term & $0.020-8.715$ & $0.012-5.375$ & 0.240 \\
\cline { 2 - 4 } & Long - term & $0.011-4.964$ & $0.014-5.984$ & 0.469 \\
\hline
\end{tabular}

*Significantly lower concentration inside the mask compared to outside ( $p$-value $<0.05$ ) according to the Wilcoxon-Mann-Whitney test

In this study, some voluntary knapsack sprayers had a health risk from airborne PQ exposure that was the highest percentage of unacceptable risk based on the estimated HQ of long-term and shortterm exposure, respectively. Moreover, the lowest inhalation risk of the sprayers was found when considering a specific organ in chronic pneumonitis. HQ estimations in this study (outside and inside the 
respirator) indicated unacceptable risk by using a different assessment method on exposure to PQ to previous studies [1,6]. Some knapsack sprayers had a health risk from exposure to PQ, although the average concentrations inside and outside the respirator were lower than the standards recommended by different organizations $[2,12,13]$. This is consistent with the experience of adverse symptoms reported by knapsack sprayers, which appeared to be related to the respiratory system, such as throat irritation (51.72 $\%)$, nose irritation $(20.69 \%)$, wheezing and difficulty breathing $(13.79 \%)$, as shown in these findings. Throat irritation, which is an acute effect and specific to short-term exposure to PQ, mainly confirmed the previous report of PQ toxicity [7,11].

It was demonstrated in this study that levels of health risk were lowered when using the respirators; however, only the standard cup-shaped mask and cartridge respirator significantly reduced the health risks of both long-term and short-term effects compared to spraying without respirators. Therefore, the type of respirator selected could also affect the risk, and use of specified respirators, i.e. cartridge and cup-shaped mask, could be recommended to the sprayers as this finding shows it could reduce the acute effects of throat irritation and other related respiratory symptoms. Hence, this risk estimation meant that health monitoring was recommended; serum uric acid level, white blood cell counts or urinary paraquat concentration determination, had been previously reported as biomarkers of PQ exposure [19]. According to that biomarker detection, a previous study of an ambient air PQ concentration which was 800 times higher than our simulated condition found a PQ biomarker detected in urine at the end of the spraying which was significantly higher than that detected before spraying ( $p$-value $<0.001)$ [20]. This is necessary for a surveillance program which supports the optimization of respirator use during PQ spraying for self- protection.

Limitations of the risk estimation in this study were due to having no reference concentration through the breathing model of PQ exposure. In this study, it was necessary to use a reference oral dose for representative HQ estimation of the knapsack sprayers with a high outdoor workload that could lead to the inhalation of airborne PQ though both routes of intake during spray operations: the mouth and nose. Furthermore, PQ concentrations during the spray operations of the knapsack sprayers should be measured by personal airborne monitoring in the field along with the biomarker detection of PQ exposure in the next study.

\section{Conclusions}

The results revealed that under the simulated control conditions of spraying PQ dichloride $(2.5 \mathrm{ml}$ in $500 \mathrm{ml}$ water $(\mathrm{v} / \mathrm{V}))$ for airborne PQ lower than $50 \mu \mathrm{g} / \mathrm{m}^{3}$ in the testing chamber, which is the occupational exposure limit value), the estimated health risk from PQ exposure during that spraying operation was unacceptable for some sprayers. The average PQ concentrations inside the certified respirators were significantly lower than outside of the respirators $\left(4.30 \pm 2.63 \mu \mathrm{g} / \mathrm{m}^{3} \mathrm{vs} .19 .12 \pm 16.65\right.$ $\left.\mu \mathrm{g} / \mathrm{m}^{3}\right)$; that was not seen with the convenient sponge mask, a common type used by the sprayers. The cartridge respirator and cup-shaped mask significantly decreased the risk estimation (hazard quotient) of the sprayers with regard to adverse health effects both from short-term and long-term PQ exposure ( $p$ value $<0.05)$. Hence, it is important that this information is communicated to both institutes related to public health and farmers, for preventive action on exposure to PQ by the use of qualified respirators or masks to protect against inhalation of PQ and decrease health risks.

\section{Acknowledgements}

This study was financially supported by the National Council of Research of Thailand (NRCT 6200101).

\section{References}

[1] MM Morshed, D Omar, R Mohamad, S Wahed and MA Rahman. Airborne paraquat measurement and its exposure to spray operators. Int. J. Agric. Biol. 2010; 12, 679-84.

[2] National Institute for Occupational Safety and Health (NIOSH) Recommended Exposure Limits (RELs) from the NIOSH Pocket Guide to Chemical Hazards, Available at: https://www.cdc.gov/niosh/npg, accessed April 2020.

[3] GZ Fortenberry, J Beckman, A Schwartz, JB Prado, LS Graham, S Higgins, et al. Magnitude and characteristics of acute paraquat and diquat related illnesses in the US: 1998-2013. Environ. Res. 2016; 146, 191-9. 
[4] H Kumar, VB Singh, BL Meena, S Gaur and R Singla. Paraquat poisoning: A case report. $J$. Clindiagn Res. 2016; 2, 10-1.

[5] VS Patil and GV Patil. A study of paraquat poisoning. Int. J. Sci. Res. 2016; 3, 118-21.

[6] C Chakkhonburi ana S Chaiklieng. Health risk assessment on paraquat exposure of knapsack sprayers. Saf. Environ. Rev. 2017; 1, 23-30.

[7] P Phetphung. Health effects of paraquat use and risk management at Pongsanuk Sub-district, Wiangsa district, Nan province (in Thai). Thai J. Pharm. Pract. 2015; 2, 250-8.

[8] Department of agriculture. Report of hazardous substance import in Thailand 2019, Available at: http://www.doa.go.th/ard/?page_id=386, accessed May 2020.

[9] Ministry of public health of Thailand. Health data center, Available at: https://hdcservice.moph.go.th/hdc/main/index_pk.php, accessed May 2020.

[10] S Chaiklieng and S Nonkratoke. Risk assessment on pesticide exposure by biological monitoring among farmers: A case study in Tambon Kangsanamnang, Nakhonratchasima Province. Srinagarind Med J. 2013; 3, 382-9.

[11] S Chaiklieng. Toxicology in public health. Khon Kaen University Printing, Khon Kaen, Thailand, 2014.

[12] American Conference of Governmental Industrial Hygienists. TLVs and BEIs. United State, 2019.

[13] Department of Labor Protection and Welfare issued in concentration limit of chemical hazard at workplace, Available at: http://www.ratchakitcha.soc.go.th/RKJ/announce/search_result.jsp?SID= 55E6506DD21DCFE93B7675E8F1417CC5, accessed May 2020.

[14] National Institute of Occupational Safety and Health. NIOSH manual of analytical methods (NMAM), Available at: https://www.cdc.gov/niosh/docs/2003-154/pdfs/5003.pdf, accessed April 2020.

[15] US.EPA. Risk assessment guidance for superfund volume I: Human health evaluation manual supplemental guidance "Standard default exposure factors" interim final. US.EPA, United State: Washington DC, 1991.

[16] European commission. Paraquat, 2003, Available at: http://ec.europa.eu/food/plant/pesticides/eupesticides-database/public/?event=activesubstance.detail\&language=EN\&selectedID=1669, accessed May 2020.

[17] Integrated Risk Information System (IRIS): United States Environmental Protection Agency. Paraqua, Available at: https://cfpub.epa.gov/ncea/iris2/chemicallanding.cfm?substance_nmbr=183, accessed April 2020.

[18] California Division of Occupational Safety and Health (Cal/OSHA) Permissible Exposure Limits (PELs) from Table AC-1 last viewed October 2, 2019, Available at http://www.dir.ca.gov/title8/5155table_ac1.html, accessed April 2020.

[19] Q Xu, X Wang, Q Wu, X Jian, B Kān, B Gao and K Wang. Urinary paraquat concentration and white blood cell count as prognostic factors in paraquat poisoning. Trop. J. Pharmaceut. Res. 2018; 17, 1391-6.

[20] P Konthonbut, P Kongtip, N Nankongnab, M Tipayamongkholgul, W Yoosook and S Woskie. Paraquat exposure of backpack sprayers in agricultural area in Thailand. Hum. Ecol. Risk Assess. Int. J. 2020; 10, 2798-811. 